\title{
ANALYSIS OF THE NECESSITY TO PROMOTE GIRLS' RUGBY SEVENS IN ROMANIAN SCHOOLS
}

\section{Ana-Maria ȘURUBA-RUSEN (VASILIU) ${ }^{1 *}$, Dan BADEA ${ }^{1}$, Manuel CARABIAS HERRERO ${ }^{2}$}

\author{
${ }^{1}$ National University of Physical Education and Sport, Faculty of Physical Education and Sport, Bucharest, \\ Romania \\ ${ }^{2}$ Deportivo Chane Club, Chane, Spain \\ *Corresponding author: ana_vasiliu85@yahoo.com
}

https://doi.org/10.35189/dpeskj.2020.59.3.3

\begin{abstract}
The present research is a sequence of the "Coaching Rugby 7 s to Girls" project, which aims to improve the skills of coaches interested in girls' rugby. There are only 4 women's rugby teams in Romania with about 60-70 players, of which only 30\% are from our country. The small number of females who practise this sport makes the selection and competition difficult. Our research aims to highlight the vulnerabilities faced by rugby coaches and female rugby athletes and find solutions for eliminating or diminishing prejudices like parents' fears of letting their daughters practise a sport that can be considered tough. The research was carried out over a period of 3 weeks. The participants are 34 female rugby players and 31 rugby specialists. The research methods used are: scientific documentation, survey, mathematical and statistical method, graphical method. The results provide important data for knowing the challenges faced by coaches and women's rugby $7 \mathrm{~s}$ players in their activity and possible solutions to reduce them. Based on the results obtained, we consider it necessary to develop a strategy to promote women's rugby among the school population, highlighting the formative values of this sport with the goal of changing the mentality about the game of rugby and convincing girls to practise it.
\end{abstract}

Keywords: girls' rugby sevens, coach training, schools, promotion, quality of life.

\section{Introduction}

Sevens is an Olympic sport for men and women and will feature at the next Olympic Games. The Olympic sport of Rugby Sevens is now 137 years old, being ‘born' in 1883.

Rugby is a sport defined by passion, discipline, solidarity, respect and integrity, values that are included in the World Rugby Playing Charter document.

Rugby Sevens is played by seven players, and the duration of the game is shorter, each half lasting only seven minutes during stages of the tournament. The length of the final game increases to ten minutes for each half.

2017 was a record-breaking for the celebration of women's rugby: the 2017 Women's Rugby Cup played a significant part in what was a wonderful year for women's sport broadcast in primetime on a TV channel in the UK on a Saturday evening, the final match attracted a peak of audience of 2.65 million on TV1 alone.

There are close to 1.76 million registered and unregistered female players globally. The game of rugby is the same for girls and boys; however, it is important to understand that boys and girls are different.

According to the Ministry of Sport in Romania, in 2016, there were 2901 registered senior athletes, of which 721 males and 60 females, 1381 registered youth athletes (1296 males and 
85 females) and 739 children. In 2019, there are only 4 women's rugby teams in Romania with about $60-70$ players, of which only $30 \%$ are from our country. The number of registered rugby players is 11,860 , and the total number of players is 57,960. Approximately 200 rugby coaches work in Romania, in a population of 19.41 million citizens in 2019, according to Eurostat.

Rugby in Romania and all over the world is male-dominated and controlled. Coaches usually focus on the development of rugby for boys and men, and little support is given to the growth of women's rugby. In the last years, rugby has begun to deteriorate in Romania. Also, the disqualification of Romania's national team for the 2019 World Cup in Japan has fired an alarm signal on this game in our country.

In an article regarding the beginnings of women's rugby players, Curtin (2016) reveals that women have been playing rugby for more than 100 years in New Zealand; the women's foray into the hyper-masculinised team sport of rugby challenged dominant sensibilities but was not wholly resisted.

Kerr (2019) is interested in discovering the motivation to start playing rugby and continue to play, and identifies as main reasons: achievement, success, team environment, friendship.

The need to promote rugby, especially among girls, is a problem in many countries. For instance, in France, women's access to rugby was only opened in 1989, according to Joncheray \& Tlili (2013), who conducted a survey (interviewed 15 people belonging to the world of French rugby and about 200 female players) to see whether there were still social barriers to women's rugby. The results showed that they mainly feared physical risk, injury and, to a lesser extent, social risk, given that they might become more masculine.

Cleary (2000) states that the perception of rugby as a men-only sport is present in New Zealand too, but women's rugby players have succeeded to transcend their socially-defined embodiment and play rugby with enthusiasm and motivation given by the encouragement of seeing other female rugby players.

Ezzell (2009) states that gender inequality is caused by people who comment on women's rugby players, so they have to deal with encountered sexist and homophobic stigmas from outsiders. Consequently, they need to face two important challenges: on the field, by playing a tough sport, and outside the field, because of comments and prejudices.

Lemez et al. (2016) show that biases occur in sport competitions due to the inconsistency given by the age difference between players who participate in the same competition. But this mismatch reveals another problem, namely the insufficient number of female rugby players. In Romania, for example, there are not enough women's rugby players, so it is not possible to organize competitions for different age groups because there are only 4 teams. Therefore, this leads to the need for better promoting this sport in our country. The age selection could be changed, in the sense that we could start selecting girls to play rugby at a younger age, such as 10 years or less. Because selection starts even earlier in other sports, most girls already practise a sport at 10 or 12 years old. So, we need a good strategy to convince parents, teachers and girls to come and find out about this sport, and to convince them that the biases are not real. We can also adapt this sport for girls: for instance, in Spain, women train with a smaller ball - size 4 (men play with a size- 5 ball).

Regarding the need to promote rugby in schools, Pringle (2008) pays attention to the impact of illustrating collective stories, as pedagogical tools, about rugby players "silenced 
and marginalised by dominant cultural narratives" (p. 215). These collective stories can be used within schools to help raise awareness of the relationships between sport, physical education and gendered identities in order to get empathetic responses and better understand that practising rugby does not affect identity. We think that understanding that this is not just a men's sport could help increase girls' interest in practising this sport and make them feel understood and appreciated by the community.

Murray and Howat (2009) talk about the enrichment hypothesis, which involves the need to provide support and awareness for the girls who decide to choose a non-traditional sport requiring body contact and physical power. The above authors also conducted interviews with 40 women's rugby players from South Australia to examine their motivations: why they initially got involved in rugby and what kept them participating. The findings of this study suggest that participants got involved for three major reasons: they knew other female rugby players, had supportive families involved in sport, and due to the social element of participation as a key ongoing motivator.

Promoting women's rugby players and competitions might have an impact on the development of this sport and the formation of a national identity, like in New Zealand. There, this was possible with the support of women from the middle and lower classes of New Zealand society, who supported rugby competitions since the 1870 s as spectators, supporters and fans. Female rugby players also increased the popularity of this sport and helped it become a national game. (Curtin, 2015)

McSharry (2017) conducted a survey in the Republic of Ireland, which was focused on the inequalities experienced by girls attending secondary schools where specific male sports dominated school life: Gaelic football, hurling and rugby. By attending these schools, girls experienced inequalities in obtaining recognition in sport and discrimination in accessing male-orientated sports, as well as unequal opportunities, resources and support. The above author points out that inequalities are due to school management, teachers and students (both male and female), who often protect this male preserve by strategies that maintain the exclusion of girls through the normalisation of gender binaries.

So, we realize that we are not only facing the prejudices of parents, girls and the community in general but also of teachers and people involved in school management, who should be the first to promote gender equality and enable girls to practise the sport they like.

A possible solution to increase interest in rugby and lower the age at which students are introduced to the game of rugby is Rookie Rugby, known in Romania as Tag Rugby. Oslen et al. (2011) present this alternative as a fun sport created for physical education classes because the game of rugby involves teamwork discipline, a sense of community and respect.

\section{Methodology}

\section{Participants}

We conducted a small-scale research on women's rugby players (34 players responded to our questions) and also rugby coaches (31 coaches from more than 25 rugby clubs) from different national rugby clubs in Romania. 


\section{Instruments}

We have developed 2 questionnaires: the first has 12 questions and is addressed to female rugby players; the second has 10 questions and is addressed to specialists in rugby (most of them are rugby coaches). The questions are either open-ended or closed-ended and refer to: the level of development of women's rugby in Romania, what influenced girls to play rugby, what makes them keep playing rugby, how to promote rugby, aspects regarding the need to tailor rugby training to gender.

Our research took place over a period of 3 weeks.

The research methods used are: scientific documentation, survey, mathematical and statistical method, graphical method.

\section{Results}

The results of the research provide important data for understanding the challenges faced by coaches and specialists in women's rugby $7 \mathrm{~s}$ : the need to promote women's rugby in schools, how to select girl athletes, what makes athletes continue to play rugby, if their training should be different from that of boys, and how women's rugby could be promoted.

The opinions of female rugby players and rugby specialists regarding rugby development in Romania are shown in Table 1.

Table 1. Opinions of female rugby players and rugby specialists regarding rugby development in Romania

\begin{tabular}{ccc}
\hline $\begin{array}{c}\text { In recent years, has women's } \\
\text { rugby developed in Romania? }\end{array}$ & $\begin{array}{c}\text { Female rugby players } \\
(\mathrm{n}=34)\end{array}$ & $\begin{array}{c}\text { Rugby specialists } \\
(\mathrm{n}=31)\end{array}$ \\
\hline Yes & $57.5 \%$ & $54.8 \%$ \\
No & $42.4 \%$ & $45.2 \%$ \\
\hline
\end{tabular}

Regarding rugby development in Romania, the respondents' opinions are almost equally divided: $57.5 \%$ of female rugby players and $54.8 \%$ of rugby specialists believe that women's rugby has developed in Romania in recent years.

As for the factors that influenced girls to play rugby, we identify a multitude of responses:

- Schools: high school, middle school, sports school, with the help of a coach or a teacher;

- A family member who had played or was still playing rugby: an uncle, a sister, someone who had taken them to a training session;

- Curiosity to try this sport;

- A friend or a colleague practising rugby, who invited them to watch a game, and they found it interesting to try it and play it;

- Their passion for sports, in general, and going to rugby training sessions convinced them that this sport was suitable for them.

- Some rugby players switched from tag rugby to rugby.

- Other respondents had played other sports before rugby: "I had to choose another sport when the handball section of the Sports High School in Kishinau was abolished", 
"The former coach took me from the school's handball team", "I did sports as a child, and when I went to high school, I was selected for rugby and since then we share the same life".

So, the multitude of responses obtained regarding the factors that influence girls' decision to play rugby indicates that they need to be informed and recruited to try and play this game.

Some aspects related to the need to tailor rugby training according to gender are shown in Table 2.

Table 2. Aspects regarding the need to tailor rugby training according to gender

\begin{tabular}{lccc}
\hline \multicolumn{1}{c}{ Category of respondents } & \multicolumn{1}{c}{ Question } & \multicolumn{2}{c}{ Response options } \\
\hline $\begin{array}{l}\text { Female rugby players } \\
(\mathrm{n}=34)\end{array}$ & $\begin{array}{c}\text { Do you think that the behaviour of coaches is } \\
\text { appropriate to your feminine characteristics? }\end{array}$ & Yes 88.2\% & No 11.8\% \\
$\begin{array}{l}\text { Specialists in rugby }(\mathrm{n}=31) \\
\text { Specialists in rugby }(\mathrm{n}=31)\end{array}$ & $\begin{array}{c}\text { Should rugby training be tailored to gender? } \\
\text { Would you attend workshops/seminars } \\
\text { dedicated to women's rugby? }\end{array}$ & $\begin{array}{c}\text { Yes 90.3\% } \\
\text { Yes 93.5\% }\end{array}$ & $\begin{array}{c}\text { No 9.7\% } \\
\text { No 6.5\% }\end{array}$ \\
\hline
\end{tabular}

Regarding training sessions, $90.3 \%$ of the surveyed specialists who work with women's rugby $7 \mathrm{~s}$ players believe that rugby training should be tailored to gender specificities. However, not all specialists (93.5\%) would participate in workshops/seminars dedicated to women's rugby. Also, a part of women's rugby players $(11.8 \%)$ think that male coaches should invest more in their training methods because they are not psychologically prepared for the difficulties they may encounter in working with girls.

From an open-ended question about the main reasons why girls continue to play rugby, we find out the following:

- It is a fair game that builds beautiful characters; I had a pretty good experience in my career and I would like to experience again the feelings I had;

- It is a pleasant, educational sport;

- It is a beautiful sport that deserves to be practised; it is a unique sport, a great sport and everyone should try it; it is a beautiful game; it is not as difficult as some think;

- It is a wonderful team sport that gives you confidence; it is an educational sport; it is a beautiful and interesting sport;

- It develops you both physically and mentally;

- It is a sport that helps physical, mental and emotional development; it prepares you from all points of view for the steps of life;

- It gives beautiful memories;

- It is a sport that helps a person to develop, especially at a rational level; it is a pleasant sport that makes life be seen from another angle;

- It motivates you in many ways; it is a game that deserves many sacrifices and responsibility;

- It helps personal development, teaches you how to react in some situations; it is a difficult but fun sport by which you learn to be disciplined, to develop your motor abilities and skills, endurance, immunity and friendships, to integrate into society, to fall down and rise up again, in other words, it prepares you for life; 
- It involves both the physical and harmonious development of the body and the health status; it is a team sport that develops you as a person; it is a way to interact with other people;

- In rugby, you find new friends, and it is usually a very clever sport; it is not only a physical but also a mind sport because you have to think and put your knowledge into practice; it develops very strong character traits;

- It develops many qualities: a beautiful character, team spirit and teamwork, willpower, in addition to physical abilities; it is a noble sport.

Regarding the issue of developing girls' rugby $7 \mathrm{~s}$ and attracting more girls to play rugby, we asked female players and specialists for their opinions. Women's rugby players have responded as follows:

- The majority of players are recruited from middle schools and high schools, and $76.5 \%$ of them want to make a career out of playing/coaching rugby;

- Most players believe that rugby can be promoted in Romania by: playing more demonstration matches in middle schools/ high schools/ universities to show how beautiful this sport is and that it is not as tough as it seems; organizing more competitions; organizing different campaigns in middle schools and high schools; promoting this sport in middle schools/ high schools by coaches or club representatives; organizing recruitment campaigns in schools; ensuring media coverage for the National Championship, Romanian Cup, European Championship; ensuring media coverage for female rugby players (TV shows/interviews, etc.); the participation of female rugby players in various charity/ volunteering/ sporting/ cultural events, and not only; motivating new girls with gifts/ sport equipment after competitions/ promotions in this sport; granting scholarships to attract girl students to practise this sport; involving physical education teachers, coaches and the Romanian Rugby Federation.

- A part of women's rugby players think that male coaches should invest more in their training methods because they are not psychologically prepared for the difficulties they may encounter in working with girls.

- The main needs of female players are: to participate in more competitions; to have the same opportunities as male rugby players; to see more involvement from the Romanian Rugby Federation - visiting clubs across the country, supporting them with equipment, travelling, organizing more women's tournaments, etc.; to enjoy more appropriate sports venues and changing rooms for girls; to benefit from internships and/or training courses in other countries; to request rugby clubs to set up female teams;

According to the rugby coaches' responses:

- $90.3 \%$ believe that rugby training should be tailored to gender specificities;

- $93.5 \%$ would participate in workshops/seminars dedicated to women's rugby;

- The Rugby Federation should create female rugby coach positions in clubs that are willing to play women's rugby;

- There is a need to train Rugby 7s coaches because it is so different from Rugby 15s; 
- Accredited continuing training courses for teachers with rugby specialisation are needed;

- There is a need for transferable credit training courses for female rugby players.

- There is a need for greater involvement of sport teachers in providing sport equipment.

Investments are needed to attract and raise this sport in Romania, as the respondents of this study mentioned: sponsorship and equipment would help girls play in proper conditions.

It is also necessary to: arrange rugby fields and locker rooms (they already exist, but there is no budget for new grounds and locker rooms), etc.; create several sports facilities dedicated to juniors; provide financial conditions and incentives to raise the motivation of senior players; offer bonuses to motivate players to attend training every day; grant scholarships to attract girl students to practise this sport; motivate new girls with gifts/ sport equipment after competitions/ promotions in this sport, etc.; set up an Olympic Centre where girls can have a school, housing and a canteen in the same yard (and this should not remain just a promise); organize training courses in other countries and continuing training courses for coaches/ trainers; see that the Romanian Rugby Federation gets more involved in visiting clubs across the country, supporting them with equipment, travelling, organizing more women's tournaments, etc.; organize courses with coaches dedicated to women's rugby; give clubs legal benefits for the development of women's rugby as an Olympic sport; see more seriousness and interest from the authorities; organize centres where the Romanian Rugby Federation can provide accommodation, meals, schooling, scholarships, etc.

More information should be disseminated in universities, high schools and middle schools to change the mentality of those who think that rugby is just a men's sport, including here parents, who may fear that their daughters will be hurt.

Convincing teachers to get involved, informing parents and children about this sport and involving national and local authorities could be a success in promoting rugby as a way to improve the quality of life of participants. We believe that it is necessary to promote rugby at national level, including in rural areas. This can be achieved by collaborating with sports teachers, organizing meetings to promote women's rugby, and participating with students in rugby 7 s competitions just to watch.

Volunteering done by active players during sport classes, within a well-established programme with the school management, would be another good initiative. Thus, players could show students that rugby can become an example to follow in life and also the benefits they can have from practising this sport.

We consider it useful to create a school rugby championship for girls (starting with middle school), as well as rugby competitions dedicated to girls but also mixed ones, both between schools and between clubs.

We recommend organizing rugby demonstration classes in several high schools/ universities to prove how beautiful this sport is and that it is not as tough as it seems, and also the national and international advantages of practising this sport.

It is possible to organize leisure motor activities, for example, one day a week in as many cities (areas of the country) that are representative of Romanian rugby, with two hours of outdoor movement (on the field), where to include a tag rugby game. Many will come for a 
little exercise and with the thought that they will feel good and improve their quality of life. This is well received by all ages. Along the way, we have noticed that participants who have children learn about this sport and may be interested in whether there are teams where their little ones can really practise this sport.

\section{Conclusion}

Given that girls may tend to be more people-orientated, how a coach gets engaged and communicates with them is very important as this sets a foundation for their learning and encourages their participation. Girls respond more positively when their coach knows them as individuals and understands their personalities, motivations and goals. Girls tend to ask more questions than boys as they usually need to understand the details of an instruction before willingly completing it, because the process is as important as the outcome.

Coaches may need to use a full range of questioning and demonstration strategies (for example, involving experienced players to demonstrate the use of videos). Physical differences between boys and girls aged 10 to 12 are usually minimal.

The game of rugby sevens for girls needs more media coverage. This sport can be promoted through TV and print advertising. We should not always watch only football on $\mathrm{TV}$, we also need to watch rugby. For example, in middle schools, high schools and universities, campaigns can be carried out to promote women's rugby. A coach or a club representative could visit middle schools/ high schools/ universities to present and promote this sport. Also, some players could go to middle schools and high schools to explain for the girls what rugby means and their experience in this sport.

Promoting women's rugby could start by broadcasting on TV channels the National Championship and the Romanian Cup, also offering media coverage for the European Championship (we do not mean media coverage only on social networks - Facebook, Instagram, but also on TV, in the newspapers, by posters, etc., through TV shows, interviews, and more). Also, female rugby players could be invited to participate in various charitable/ volunteering/ sporting/ cultural events or play demonstration games.

We propose a rigorous selection for an average-investment pilot programme and the identification of a coach to be involved in this project. For example, in Bucharest, tag rugby competitions can be organized in middle schools and high schools by age, starting with the 5 th grade. Students from two grades with a 2-year age difference can be part of a team (for instance, students in the 5th and 6th grades), up to high schools. The same can be done in high schools; we recommend making up teams with players whose age difference is no more than 2 years. Then, keeping the age criterion, competitions can be organized to select middleschool and high-school teams within a sectoral phase in Bucharest, following that the finalists play this phase in the capital city. This can also be organized in universities. A competition of the faculties within universities, and then a competition between selected universities can be organized in Bucharest. There can be a final tournament organized in a Romanian city for all university teams throughout the country. 


\section{Authors' Contributions}

All authors have contributed equally to this study and should be considered as main authors.

\section{References}

Cleary, A. (2000). Rugby women. Annals of Leisure Research, 3(1), 21-32. https://doi.org/10.1080/11745398.2000.10600883

Curtin, J. (2016). Before the 'Black Ferns': Tracing the beginnings of women's rugby in New Zealand. The International Journal of the History of Sport, 33(17), 2071-2085. https://doi.org/10.1080/09523367.2017.1329201

Curtin, J. (2015). More than male-gazing: Reflections on female fans of Rugby Union in New Zealand, 1870-1920. The International Journal of the History of Sport, 32(18), 2123-2134. http://dx.doi.org/10.1080/09523367.2015.1005609

Ezzell, M. B. (2009). "Barbie Dolls" on the pitch: Identity work, defensive othering, and inequality in women's rugby. Social Problems, 56(1), 111-131. https://doi.org/10.1525/sp.2009.56.1.111

Joncheray, H. \& Tlili, H. (2013). Are there still social barriers to women's rugby? Sport in Society, 16(6), 772-788. https://doi.org/10.1080/17430437.2012.753528

Kerr, J. H. (2019). The multifaceted nature of participation motivation in elite Canadian Women Rugby Union players. International Journal of Sport and Exercise Psychology, 116. https://doi.org/10.1080/1612197X.2019.1611904

Lemez, S., MacMahon, C., \& Weir, P. (2016). Relative age effects in Women's Rugby Union from developmental leagues to World Cup tournaments. Research Quarterly for Exercise and Sport, 87(1), 59-67. https://doi.org/10.1080/02701367.2015.1116120

McSharry, M. (2017). 'It's just because we're girls': How female students experience and negotiate masculinist school sport. Irish Educational Studies, 36(3), 341-356. https://doi.org/10.1080/03323315.2017.1327366

Murray, D., \& Howat, G. (2009). The 'enrichment hypothesis' as an explanation of women's participation in rugby. Annals of Leisure Research, 12(1), 65-82. https://doi.org/10.1080/11745398.2009.9686809

Oslen, E. B., Caram, C., \& Griffin, M. (2011). Teaching youth rugby: Instructional strategies and models that work. Strategies, 24(6), 8-12. https://doi.org/10.1080/08924562.2011.10590955

Pringle, R. (2008). 'No rugby - no fear': Collective stories, masculinities and transformative possibilities in schools. Sport, Education and Society, 13(2), 215-237. https://doi.org/10.1080/13573320801957103 